\title{
Acute pancreatitis and superior mesenteric artery syndrome
}

\author{
Denisse Joan Sihuay-Diburga, Anna Accarino-Garaventa, Jaime Vilaseca-Montplet and Fernando \\ Azpiroz-Vidaur
}

Department of Gastroenterology. Hospital Universitario Vall d' Hebron. Universidad Autónoma de Barcelona. Barcelona, Spain

\begin{abstract}
Superior mesenteric artery syndrome (SMAS) has been proposed as a rare cause of proximal bowel obstruction resulting from compression of the third portion of the duodenum secondary to narrowing of the space between the aorta and superior mesenteric artery. The main risk factors associated with SMAS are significant weight loss, corrective spinal surgery and congenital or acquired anatomic abnormalities. Its association with acute pancreatitis has been reported in very few cases. We present a critical review of this topic, with the report of a patient allegedly diagnosed of SMAS and acute pancreatitis.
\end{abstract}

Key words: Superior mesenteric artery syndrome. Pancreatitis.

\section{CASE REPORT}

A 28-year-old Caucasian woman, with a medical history of cerebral palsy, spastic quadriplegia and seizures treated with phenobarbital, was admitted to the emergency department with a 24 hour history of abdominal distension, bilious vomiting and fever of $38{ }^{\circ} \mathrm{C}$. On admission, the patient's vital signs were stable. Physical examination revealed a cachectic young woman (BMI: $18 \mathrm{~kg} / \mathrm{m}^{2}$ ), with a soft, non-tender but distended abdomen, predominantly in the epigastrium.

Under the suspicion of proximal bowel obstruction, a nasogastric tube was inserted, with abundant bilious fluid output, and additional tests were performed: Abdominal $\mathrm{X}$-ray showed dilatation of the stomach without air-fluid levels; laboratory data showed hemoglobin $18 \mathrm{~g} / \mathrm{dL}$ with

Received: 05-09-2012

Accepted: 10-07-2013

Correspondence: Denisse Joan Sihuay Diburga. Department of Gastroenterology. Hospital Universitario Vall d’Hebron. Passeig de la Vall d’Hebrón, 119-129. 08035 Barcelona, Spain

e-mail: desidi31@ @otmail.com
MCV $88 \mathrm{fL}$, white cell count 17,200 with neutrophilia $87 \%$, amylase $500 \mathrm{U} / \mathrm{L}$ (normal $<53 \mathrm{U} / \mathrm{L}$ ), lipase 628 $\mathrm{U} / \mathrm{L}$ (normal $<67 \mathrm{U} / \mathrm{L}$ ), trypsin $6,990 \mu \mathrm{g} / \mathrm{L}$ (normal $<440$ $\mu \mathrm{g} / \mathrm{L}$ ), and amylasuria $480 \mathrm{U} / \mathrm{L}$ (normal < $350 \mathrm{U} / \mathrm{L}$ ); indicators of renal and liver function and electrolytes were normal. Abdominal X-ray after gastografin administration revealed a grossly dilated stomach and duodenum with late passage of contrast to the small intestine.

In view of these findings suggestive of partial bowel obstruction at duodenal level, a CT scan performed showed gastric and duodenal distension to the aortomesenteric angle, with a reduced distance between the aorta and SMA (Fig. 1). Glandular necrosis of the head and tail of the pancreas with fat infiltration and free fluid in both paracolic gutters consistent with Balthazar grade D was also observed. The intra- and extra-hepatic biliary tract was normal (Fig. 2).

During admission, the patient was maintained on total parenteral nutrition, and a continuous nasogastric aspiration tube was inserted which yielded a high debit (around $2,000 \mathrm{~mL} /$ day) of bilious liquid. Blood cultures were negative and the fever self-limited. Serial determinations of amylasuria oscillated between 1,000 and 4,500 U/L for around 10 days and the condition resolved gradually after 3 weeks.

An abdominal CT scan performed prior to discharge showed resolution of the pancreatitis and dilatation of the stomach and duodenum. To rule out other possible causes of pancreatitis, abdominal US was performed, which was normal, and serology for some viruses (CMV, EBV, herpes virus, measles, rubella and varicella zoster) which were all normal. The patient was discharged and was followed for 1 year with favourable outcome.

Sihuay-Diburga DJ, Accarino-Garaventa A, Vilaseca-Montplet $J$, Azpiroz-Vidaur F. Acute pancreatitis and superior mesenteric artery syndrome. Rev Esp Enferm Dig 2013;105:626-628. 


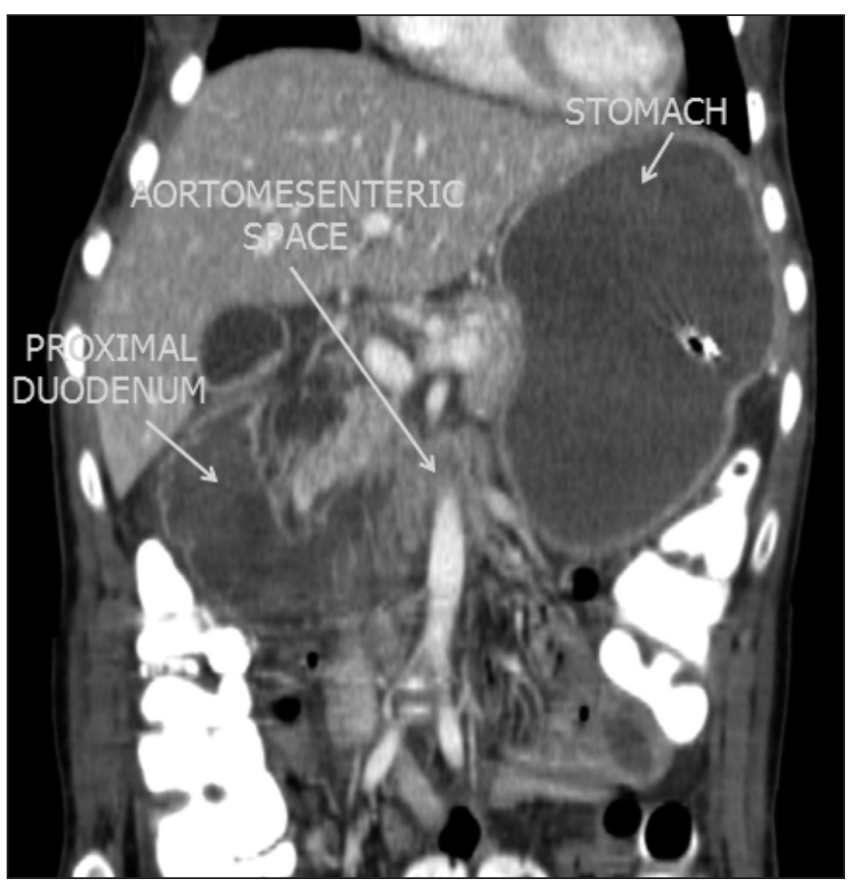

Fig. 1. Coronal image showing distension of the stomach and proximal duodenum with abrupt narrowing of the duodenum as it passes under the SMA

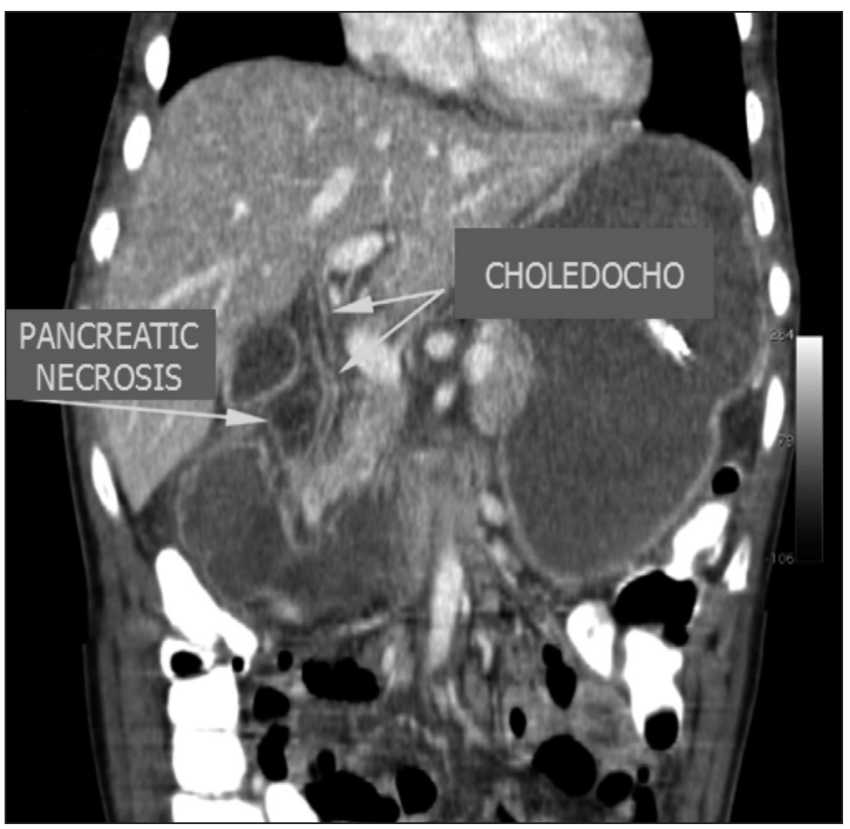

Fig. 2. Radiological findings are consistent with acute pancreatitis Balthazar grade D. The arrows indicate glandular necrosis of the pancreatic head and normal biliary tract throughout its course.

\section{DISCUSSION}

The superior mesenteric artery syndrome (SMAS) was first described by Von Rokitansky in 1861 as an obstruction of the third portion of the duodenum between the superior mesenteric artery (SMA) and the aorta. In 1921, Wilkie published the first series of 75 cases of high intestinal obstruction due to narrowing of the angle between the SMA and aorta (1). Since then, only isolated cases or small series have been published; thus, the exact prevalence of this syndrome remains unknown. A review of 1,280 barium studies showed only $10(0.78 \%)$ to be suggestive of SMAS (2).

In normal conditions, the SMA and aorta form a $45-60^{\circ}$ angle, which permits the normal passage of the third part of the duodenum. This angle remains open due to the presence of retroperitoneal fat $(3,4)$. When this retroperitoneal fat is reduced, mainly secondary to clinical conditions that generate severe weight loss, compression of the duodenum could result. It has been proposed that an angle below 15 to $20^{\circ}$ usually marks the beginning of the obstructive symptoms, which may be acute or chronic (4).

Multiple risk factors associated with SMAS have been reported: Severe weight loss (consumptive syndromes, polytrauma, large extensive burns, anorexia nervosa), diseases of the spine, including orthopaedic correction surgeries and use of corrective corsets ("cast syndrome") and congenital (short Treitz ligament) or acquired (after surgical correction of aneurysms) anatomical abnormalities (5). The BMI of our patient was $18 \mathrm{~kg} / \mathrm{m}^{2}$; she presented a deformity of the thoracolumbar spine with marked kyphosis associated with cerebral palsy and spastic quadriplegia.

However, the diagnosis of superior mesenteric artery syndrome must be viewed with caution. The differential diagnosis must be made with motility disorders, particularly of myopathic type of which a megaduodenum could be the only symptom. The most common diseases related to this kind of motility disorder are collagen diseases, especially systemic sclerosis and usually family-type chronic intestinal pseudo-obstruction. Clinical manifestations may range from trivial or dyspeptic symptoms to severe occlusive syndrome and are indistinguishable from those attributed to SMAS. Moreover, disorders considered risk factors for SMAS are known causes of secondary motility disorders (anorexia nervosa, orthopaedic surgery, etc.). In these cases, small bowel motility must be studied to differentiate these two entities $(6,7)$. In our case, given the resolution of the symptoms and the patient's general status, intestinal manometry was not performed.

The association of SMAS and acute pancreatitis is rare. Very few cases have been reported (8-12) in the MEDLINE database; of these only in one, owing to the clinical outcome, was SAMS suggested as a possible aetiology of pancreatitis (9). This was the case of a 16-year-old man with cerebral palsy and multiple episodes of mild pancreatitis initially attributed to "biliary sludge", however after image review, SMAS was suspected and the patient improved progressively, first after an initial weight gain of $4 \mathrm{~kg}$ with enteral and parenteral nutrition and, 3 years later, after surgical correction (9). Although the other cases had in common that patients had one or more risk factors for SMAS, the cause of pancreatitis was not established 
and in all of them, as in our case, abdominal US was performed, and even ERCP in some cases to rule out the main causes of pancreatitis. On occasions, the diagnosis of pancreatitis was doubtful since it was based solely on raised amylase levels, a relatively non-specific finding, which may also occur in duodenal occlusion (13). The mechanism of SMAS pancreatitis is poorly understood; the secondary occlusive postpapillary syndrome due to SMAS may produce a retrograde reflux of bile into the pancreatic duct, which would activate the inflammatory phenomena responsible for pancreatitis. Moreover, pancreatitis could also cause partial paralytic ileus or peripancreatic edema that could produce conflict in the aorto mesenteric space with involvement of the distal duodenum.

In conclusion, the relationship between narrowing of the angle between the SMA and aorta, dilatation of the proximal gastrointestinal tract and acute pancreatitis may have different interpretations, and conservative treatment such as gastroduodenal decompression, correction of electrolyte abnormalities and adequate nutritional support is recommended. Most patients recover satisfactorily, with surgical correction being required only in some cases $(14,15)$.

\section{REFERENCES}

1. Wilkie BP. Chronic duodenal ileus. Am J Med Sci 1927;173:643-50.

2. Jiménez F, Rodríguez F, Puente J, Muñoz R, Adarraga M, Zambrana L. Compresión duodenal por la arteria mesentérica superior: análisis de 10 pacientes. Rev Esp Enferm Dig 2003;95:480-4.

3. Raman SP, Neyman EG, Horton KM, Eckhauser FE, Fishman EK. Superior mesenteric artery syndrome: Spectrum of CT findings with multiplanar reconstructions and 3-D imaging. Abdom Imaging 2012;37:1079-88

4. Lippl F, Hannig C, Weiss W, Allescher HD, Classen M, Kurjak M. Superior mesenteric artery syndrome: Diagnosis and treatment from the gastroenterologist's view. J Gastroenterol 2002;37:640-3.

5. Merrett ND, Wilson RB, Cosman P, Biankin AV. Superior mesenteric artery syndrome: Diagnosis and treatment strategies. J Gastrointest Surg 2009; 13:287-92.

6. Mungan Z, Akyüz F, Bugra Z, Yönall O, Oztürk S, Acar A, et al. Familial visceral myopathy with pseudo-obstruction, megaduodenum, Barrett's esophagus, and cardiac abnormalities. Am J Gastroenterol 2003;98:2556-60.

7. Boeckxstaens GE, Rumessen JJ, de Wit L, Tytgat GN, Vanderwinden JM. Abnormal distribution of the interstitial cells of cajal in an adult patient with pseudo-obstruction and megaduodenum. Am J Gastroenterol 2002;97:2120-6.

8. Gwee K, Teh A, Huang Ch. Acute superior mesenteric artery syndrome and pancreatitis in anorexia nervosa. Australas Psychiatry 2010;18: 523-6.

9. Arbell D, Gross E, Koplewitz B, Vromen A, Bar-Ziv J, Udassin R. Superior mesenteric artery syndrome masquerading as recurrent biliary pancreatitis. Isr Med Assoc J 2006;8:441-2.

10. Cremonte LG, Mantellini E. Associazone di pancreatite acuta ed infarto intestinale da oclussione dell' arteria mesenterica superiore. Minerva Med 1989;80:505-6.

11. Petrosyan M, Estrada JJ, Giuliani S, Williams M, Rosen H, Mason RJ. Gastric perforation and pancreatitis manifesting after an inadvertent nissen fundoplication in a patient with superior mesenteric artery syndrome. Case Rep Med 2009;2009:426162.

12. Ammaturo C, Giardello C, Piscitelli L. The superior mesenteric artery syndrome: A rare cause of acute pancreatitis. Panminerva Med 1988;30:114-7

13. Feiss JS, Goldenberg AL, Plevy DJ, Luckman GS. Superior mesenteric artery syndrome simulating acute pancreatitis: A case report. Am J Gastroenterol 1976;66:476-9.

14. Richardson W, Surowiec W. Laparoscopic repair of superior mesenteric artery syndrome. Am J Surgery 2001;18:377-8.

15. Alnabulsi BK, Miro JT, Faidah OH, Hamo MA. Laparoscopic duodenojejunostomy omega loop with braun anastomosis as a treatment for superior mesenteric artery syndrome. Saudi Med J 2011;32:188-91. 